\title{
Cultura e subjetividade - CAMPOS DE CONTINUIDADE E RUPTURA: A HISTÓRIA DE MukHTAR MaI
}

\author{
Jennifer Perroni ${ }^{1}$
}

\begin{abstract}
Resumo
No ano de 2002 a paquistanesa Mukhtar Mai foi condenada a um estupro coletivo pelo crime de seu irmão. Infelizmente situações como essa não podem ser consideradas raras no Paquistão, onde o estupro como forma de resolver conflitos entre famílias é uma prática comum. Assim, o mais impressionante nessa história talvez tenha sido justamente a reação dessa mulher que ao invés de se resignar ao silêncio ou cometer o suicídio, comum nesses casos, iniciou um processo de superação, denúncia, e luta pelos direitos das mulheres em seu país. Através dessa história podemos perceber como tradição e cultura permeiam as ações e representações de um povo onde o corpo feminino ainda representa um objeto que pode ser usado para a honra ou vergonha do clã. Mas esse mesmo sistema de valores também possibilita o surgimento de indivíduos que conseguem romper com um determinado padrão de subordinação.
\end{abstract}

Palavras-chave: Cultura. Violência de gênero. Dominação masculina.

\footnotetext{
${ }^{1}$ Graduada em Serviço Social pela Universidade Federal Fluminense. Mestranda em Política Social pela mesma instituição. Endereço eletrônico: perroni.uff@gmail.com
} 


\title{
Culture and Subjectivity - Areas of Continuity and Rupture: The History of MuKhtar MaI
}

\begin{abstract}
In 2002 a Pakistani woman named Mukhtar Mai was sentenced to collective rape for a crime committed by her brother. Unfortunately, situations like these cannot be considered rare in Pakistan, where rape as a way of resolving conflicts between families is a common practice. Consequently, the most remarkable aspect of this story may have been the reaction of this woman, who instead of resigning herself to silence or committing suicide, which is common in these cases, initiated a campaign of protest and struggle in favor of women's rights in her country. Through this story we can perceive how tradition and culture permeate the actions and representations of a people in which the femail body still represents an object that can be used for the honor or shame of the clan. But this system of values also makes possible the rise of indivuduals who are able to break with a pattern of subordination.
\end{abstract}

Keywords: Culture. Gender violence. Masculine dominance.

\section{INTRODUÇÃO}

0 Em junho de 2002 Mukhtar Mai começa a ter sua vida transformada: paquistanesa, analfabeta, divorciada e pertencente a uma casta de camponeses é informada pelos homens de sua família que deve pedir, a um clã mais poderoso, perdão por um crime cometido por seu irmão, Shakkur. 0 pedido de perdão, no entanto, é recusado e Mukhtar Mai condenada a um estupro coletivo - o que, embora cause um profundo choque em nossa sociedade, não pode ser considerado algo tão incomum àquela sociedade . De tal forma que, muito mais espantoso do que o estupro, talvez tenha sido a atitude da camponesa que, ao invés de recorrer a suicídio como forma de fugir da vergonha - o que é comum nesses casos - rompeu com os costumes e as tradições que condenam as mulheres ao silêncio e denunciou o que lhe ocorrera.

Através de seu relato Mai faz o esboço da sociedade onde cresceu: "aqui, uma mulher não determina sua própria vida. Quando vive na casa dos pais, participa de tudo que os pais querem. Uma vez vivendo com o marido, faz tudo que ele manda. Quando os filhos crescem, chega a vez deles, ela thes pertence da mesma forma" (MAI, M; CUNY, M.T, 2007, p. 87). No entanto, é 
preciso estar atento para o fato de que embora Mukhtar Mai reconheça e tenha interiorizado todos os elementos que, na sociedade em que vive, justificam 0 poder masculino - segundo Bourdieu (1996, p. 37) a dominação apenas se torna possível na medida em que o dominado tenha apreendido as estruturas pelas quais são percebidos pelos dominantes - ainda assim transgride algumas normas ao denunciar a violência sofrida e, assim, romper com um padrão de subordinação.

Dividido em duas partes o trabalho se propõe, primeiramente a tecer considerações sobre alguns elementos da cultura e da tradição presente no relato de Mai, bem como algumas especificidades em sua biografia. Acreditamos que essa análise inicial seja fundamental para compreendermos não apenas os motivos que levaram a violência como também os que possibilitaram sua superação. Por considerarmos a luta de Mukhtar emblemática no que tange a resistência, o segundo momento de nossa análise contemplará a ruptura observada em seu relato que faz com que ela não sucumba a suicídio. Nesse ponto destacamos a Escola Mukhtar Mai, como um símbolo de resistência e de transformação.

Nosso objetivo é analisar a trajetória de Mai, destacando os elementos que possibilitaram a ruptura com o padrão de subordinação típica das mulheres paquistanesas. Quanto a esse objetivo, é necessário fazer algumas ressalvas: primeiramente no que tange a fonte de dados, utilizamos a biografia escrita pela própria Mukhtar Mai com a colaboração de Marie-Thérese Curry. Assim, acreditamos que os pensamentos expressos no livro nos possibilitam uma leitura não apenas das normas e tradições as quais Mai está sujeita, como também encontramos questões mais subjetivas.

Quanto a essa fonte é importante não desconsiderar a presença do olhar de uma mulher ocidental na narrativa. Da mesma forma, é preciso estar claro que ao nos prendermos ao relato feito por Mukhtar Mai outras informações e versões nos escapam, porém nosso objetivo, muito do que garimpar a verdade, situa-se no campo das representações. Interessa-nos compreender a maneira pela qual a camponesa compreende a si e ao mundo onde vive e as transformações pelas quais passa no processo de ruptura com um determinado padrão de subordinação.

Uma segunda observação se refere ao fato de que não pretendemos, em nosso estudo, apontar de maneira paradigmática as razões que levaram Mukhtar a essa ruptura - o que representaria um academicismo muito arrogante de nossa parte. Nosso esforço se dirige sentido de pensar alguns elementos que possivelmente contribuíram para essa transformação. Por último, é preciso destacar que 0 
presente trabalho não pretende analisar a condição da mulher no Paquistão de forma genérica, o que certamente exigiria um estudo muito mais profundo do que o realizado aqui, o que nos propomos é, através da análise de um relato pensar algumas considerações sobre a vida de uma paquistanesa ${ }^{2}$. Obviamente que reconhecemos que uma micro-experiência pode refletir uma estrutura de macroprocessos através do qual é possível pensar não apenas o encontro de homens com mulheres em um contexto específico como também em relação à dicotomia entre o Outro e Eu. Processos esses permeados por diferentes formas de violência.

\section{TrAdiÇÃO, CULTURA E VIOLÊNCIA: ALGUNS ELEMENTOS PARA PENSARMOS MUKHTAR MAI}

Mukhtar Mai é uma mulher de vinte e oito anos, pertencente a uma casta de camponeses, os Gujjar. Divorciada, vive na casa de seus pais. Colabora com os rendimentos familiares ensinando bordado. Embora analfabeta, ensina 0 Corão gratuitamente a crianças da aldeia. Após a denúncia de que seu irmão teria ofendido uma casta de guerreiros - os Mastoi - é obrigada a pedir perdão em nome de sua família. 0 pedido é recusado e Mukhtar condenada a um estupro coletivo.

Essa é a história sobre a qual voltaremos nosso olhar no presente trabalho. Embora pareça se tratar de uma história como tantas outras vividas por mulheres paquistanesas, há elementos que gostaríamos de ressaltar que não apenas possibilitam compreender a cultura e costumes daquela sociedade como também nos permitem pensar as especificidades que permitiram a Mukhtar romper com 0 silêncio que comumente se abate sobre mulheres que sofrem esse tipo de violência 3 .

Antes de prosseguirmos é interessante voltamos nossa atenção para as poucas linhas que, parágrafo acima, apresentaram Mukhtar Mai. Primeiramente é necessário considerar o divórcio, um dado absolutamente fundamental para a sociedade em que vive onde é normal que "uma mulher divorciada, na nossa tradição seja malvista" (p. 99): Quando tinha dezoito anos foi escolhido para

\footnotetext{
${ }^{2}$ Para uma análise sobre a condição da mulher no Paquistão sugiro a leitura de Brooks (1996) e Espinola (2000).

${ }^{3}$ Cabe ressaltar que o silêncio em vítimas de violência não pode ser considerada uma característica exclusiva das mulheres paquistanesas. Em Zuwick (2002) é possível observar esse mesmo padrão em mulheres brasileiras.
} 
ela um marido. Como salientamos anteriormente, a vida de Mai é determinada pelos homens de sua família, assim em nenhum momento the foi perguntado se aceitava, ou mesmo se queria, o casamento ou mesmo o noivo. De fato, foi surpreendente para essa mulher que "desde a mais tenra infância só havia aprendido o silêncio" (p. 83), o questionamento do imã durante a cerimônia de casamento, se aceitava o marido: "Fiquei tão impressionada que não conseguia responder. Nem sim nem não. Não saía palavra alguma de minha garganta" (p. 95).

0 que ela poderia responder? De onde deveria escapar sua voz? Que voz ela tinha?

Foram as mulheres de sua família que responderam por ela que, afinal, casou-se da silenciosa maneira como sempre fora ensinada. Após a cerimônia, passou um mês vivendo com o marido. 0 contrato estabelecido entre as duas famílias determinava que os noivos deveriam morar, após o casamento, na casa dos pais da noiva. Assim, passado um mês Mukhtar Mai retorna a casa do pai, porém seu marido não aceita acompanhá-la, nem mesmo quis trabalhar com 0 pai de Mukhtar, nem ofereceu resistência ao talaq, o divórcio.

0 apoio que recebeu do pai é reconhecido:

Ele me apoiou no divórcio, logo que percebeu que o homem escolbido para ser meu marido não era correto, que era um inútil incapaz de cumprir seus compromissos. Ele se manteve firme, como eu, até que eu conseguisse o talaq. (...) Recuperei minha liberdade graças ao meu pai e à minha obstinação, a única força de que dispomos frente aos homens (p. 45).

Assim, não apenas Mukhtar é apoiada por sua família como já apresentava, em sua trajetória, uma experiência de enfrentamento e de sucesso. Após o divórcio Mai vive tranqüilamente na casa dos pais.

Trabalhei para ajudar minha familia a atender minhas necessidades. Entre o Corão, que ensinava como voluntária às crianças, e as aulas de bordado para as mulheres da aldeia, eu recuperava minha honra e minha respeitabilidade na comunidade (p. 99).

0 conhecimento do Corão é outra questão que nos parece fundamental. Embora analfabeta, ela admite que tudo o que aprendeu se deu pela tradição oral,

${ }^{4} 0$ imã corresponderia a uma espécie de líder da comunidade que consagra a união. 
mas que ainda assim conseguiu conhecer o bastante para ensinar as crianças de sua aldeia. É interessante perceber que, embora seja uma mulher, analfabeta, Mukhtar apresenta em sua trajetória alguns elementos que a possibilitaram romper com aquilo que poderia ser considerado comum em uma mulher paquistanesa. Ela é divorciada, tem o apoio de sua família, conhece o Corão tanto, ou melhor, do que muitos homens. Ou seja, embora absolutamente parecida com outras tantas mulheres Mukhtar Mai apresenta alguns elementos em sua biografia que a distinguem da maioria das paquistanesas.

Mukhtar reconhece em diversos momentos o peso da tradição, dos costumes e da cultura de onde vive. Ela demonstra, através de seu relato, que incorporou a hierarquia que torna uma casta submissa à outra e mulheres submissas aos homens. Segundo Ruth Benedict "a cultura é como uma lente através da qual o homem vê o mundo" (apud LARAIA, 2006, p. 67). Assim é preciso compreender que a cultura não apenas vai determinar práticas e ações, como também influi diretamente na forma como o homem percebe e se relaciona com o outro. Mukhtar Mai ao interiorizar os elementos culturais de onde vive apreendeu também a maneira como se percebe enquanto mulher e enquanto pertencente a uma casta de camponeses para essa sociedade.

A representação que Mukhtar tem de si mesma é em diversos momentos negativa, assim como reconhece que sua família é humilde e deve obediência a clãs mais poderosos. Aqui o estudo de Chartier (1990, p. 22) nos ajuda a compreender a importância das representações. Segundo o autor "a representação transformase em máquina de fabrico de respeito e submissão, num instrumento que produz constrangimentos interiorizados, que é necessário onde quer que falte o recurso da violência imediata".

A questão da representação social, portanto, é fundamental para entendermos o poder dos Mastoi - clã que, sentindo-se ofendido pela família de Mukhtar exige o pedido de perdão - nessa sociedade e o motivo pelo qual o estupro é a maneira pela qual esse clã revolve seus conflitos. Assim, cabe novamente destacar - dada à importância dessa característica - que a família de Mukhtar Mai pertence a um clã de camponeses enquanto que seus agressores são guerreiros.

Tal configuração não deve ser compreendida como uma simples divisão da atividade exercida pelas famílias. É importante apontar que a construção em torno da identidade masculina é construída em torno de símbolos de virilidade, guerra, força. É isso que os Mastoi representam naquela sociedade, eles mobilizam 
símbolos que reafirmam sua virilidade e, conseqüentemente, seu poder, de tal forma que se colocam em uma posição privilegiada em relação às demais castas. Eles detêm o controle da polícia local, a posse de terras, as armas, a representação de guerreiros. Tudo se torna símbolo de um poder que é reconhecido naquele espaço social. Mukhtar Mai é muito clara ao expressar o poder que eles possuem: "eles não temem Deus, nem o diabo, nem o mulá. Desfrutam do poder que lhes é conferido por sua casta superior. De acordo com o sistema tribal, decidem quem é o inimigo, quem deve ser esmagado, bumilhado, roubado, violado em total impunidade" (p. 27). Assim, a dominação dos Mastoi pode ser compreendida enquanto uma dominação masculina, e que, por isto mesmo, não precisa ser justificada, embora seja reafirmada através da força (BOURDIEU, 1999).

Podemos pensar, a partir do relato do livro, que nessa sociedade a honra constitui um capital simbólico ${ }^{5}$, e considerando que no Paquistão a honra do homem é justamente a mulher, então veremos que o corpo feminino também assume uma forma de capital. Assim, não chega a ser surpresa o fato de que " $a$ vingança dos Mastoi sempre recai sobre uma mulher de uma casta inferior" (p. 67). De tal maneira que nesse sistema de valores as mulheres

servem como mercadoria de troca para resolver os conflitos e receber a punição. E a punição é sempre a mesma. Embora a sexualidade seja um tabu e a honra do homem em nossa sociedade no Paquistão seja precisamente a mulher, ele só encontra como solução para um acerto de contas o casamento forçado ou o estupro (p. 101).

Novamente é a sociologia de Bourdieu que nos ajuda a compreender a relação entre a virilidade e a vingança. Para esse autor a virilidade não resume apenas a capacidade sexual do ser humano, mas também está diretamente ligada ao uso do combate, da violência, mas, sobretudo, relacionada à vingança. Bourdieu continua em sua análise demonstrando que essa virilidade, essa força, tem que ser reconhecida por outros iguais, ou seja, por outros homens para que

\footnotetext{
5 Tal como foi observado nas sociedades mediterrâneas por Bourdieu para quem "o capital simbólico é uma propriedade qualquer (de qualquer tipo de capital, físico, econômico, cultural, social), percebida pelos agentes sociais cujas categorias de percepção são tais que eles podem entendê-las (percebê-las) e reconhecê-las, atribuindo-lhes valor". Nesse ponto é fundamental o conceito de representações. Assim, uma forma de capital simbólico é reconhecida "pela representação que os outros fazem dela, na medida em que compartilham um conjunto de crenças apropriadas a fazer com que percebam e apreciem certas propriedades e certas condutas como honrosas ou desonrosas" (BOURDIEU, 1996, p. 107).
} 
seja legitimada. Assim, reconhece em rituais institucionalizados e nos estupros coletivos a afirmação da virilidade, da violência e conseqüentemente da força. Mukhtar confirma essa perspectiva de forma absolutamente simples quando diz que "os homens têm o monopólio da vingança, que passa pela violência contras as mulheres" (p. 26). Seu conhecimento se dá pela simples observação do vivido. 0 monopólio da vingança se justifica pela própria virilidade.

Por isso mesmo que o estupro representa também a dominação de uma casta e do que ela representa por outra considerada superior. Tal qual em Todorov (1991) ao analisar o corpo das mulheres indígenas violados com a chegada de espanhóis às Américas, aqui o estupro também assume uma dupla conotação: primeiramente em seu sentido mais evidente que é a dominação dos homens sobre o corpo feminino e segundo no sentindo que serve para demonstrar o poder de um clã em subjugar outro.

Assim, vemos o poder masculino sobre o corpo feminino. Seja por parte de quem pratica o estupro como o poder dos homens que entregam o corpo feminino para ser violado. Nesses dois casos o corpo feminino é um objeto que serve aos interesses dos homens, seja para quem agride, seja para quem entrega. Mas vemos também o poder de um clã que exige a entrega do corpo feminino de outro clã, então nesse caso é o discurso de um homem para outro que embora lhe seja igual - ambos são homens - é inferior por não dispor dos mesmos bens simbólicos reconhecidos naquela dada sociedade. Talvez esse seja um exemplo excessivamente literal do que Soihet (1997, p. 10) afirmou ser um "duplo discurso, do homem sobre o homem e do homem sobre a mulher".

Cabe agora tecer algumas considerações acerca do clã Gujjar - aquele ao qual Mukhtar Mai pertence. Trata-se de um clã de camponeses, ou seja, constitui um grupo que não apresenta, a priori, o caráter bélico nem carrega os elementos simbólicos atribuídos à casta guerreira. Ou seja, os Gujjar não possuem os mesmos elementos valorizados, e que naquela sociedade são tipicamente masculinos, contrário ao que ocorre com os Mastoi. Na verdade, talvez essa configuração, embora não deva ser vista de forma determinante, ajude a compreender por que a família de Mai se mostrará tão solidária em sua dor. Também eles reconhecem os elementos de submissão aos quais se encontram subordinados.

Podemos pensar que, dentro dessa lógica, o poder que a todo o instante Mukhtar Mai afirma que os Mastoi exercem sobre os Gujjar deve ser compreendido como algo que vai muito além da simples posse da arma, mas passa por toda 
uma representação onde Mastoi "pertencem a uma casta de guerreiros, e nós só temos paus para acender o fogo e nenbum aliado poderoso para nos defender" (p. 25).

Feitas essas observações, continuemos nossa análise sobre os fatos que culminaram no estupro. Shakkur de doze anos, irmão mais novo de Mai, é acusado de ter entrado nas terras dos Mastoi, e por isso ele é raptado pelos acusadores que tratam de aplicar a justiça. Aparentemente o que provoca a ira dos Mastoi é 0 fato de que o pai de Mukhtar apresenta, junto à delegacia, uma queixa quanto ao rapto. Esse ato é considerado pelos Mastoi uma afronta e, devido a isso, eles mudam a acusação, passando a alegar que Shakkur conversou com Salma, uma jovem do clã de vinte anos e posteriormente, novamente mudando a acusação, alegam que ele a violou ${ }^{6}$.

Tais acusações poderiam ser resolvidas com a morte do jovem Gujjar, com um casamento entre os clãs, ou com o estupro - o que segundo Mai não havia sido cogitado por sua família - mas também poderia ser resolvido com um simples pedido de perdão. No fim, cabe a uma mulher do clã se humilhar em um pedido de perdão. Porém, de acordo com a narrativa de Mukhtar o objetivo do clã Mastoi não era perdoar, mas sim reforçar seu poder naquela dada sociedade o que foi feito através de duas formas:

"Depois de acusá-lo desse roubo, o clã o seqüestrou, espancou e sodomizou meu irmão para bumilhá-lo" (p. 22).

Aqui novamente é preciso retomar a discussão feita anteriormente sobre a relação encontrada entre virilidade, vingança e força acrescida à violência sexual de um homem contra outro. Assim, é importante pensar a relação entre as castas e os papéis que desempenham. Não apenas os Mastoi demonstram seu poder ao violar corpos femininos como também o fazem em relação ao corpo masculino pertencente a uma casta inferior - um corpo que nesse contexto pode ser transformado em um corpo feminino.

Segundo Bourdieu (1999, p. 32), "compreende-se que, sob esse ponto de vista que liga sexualidade a poder, a pior humilhação, para um homem consiste em ser transformado em mulher". De tal forma que podermos ver, no ato de sodomizar um jovem do clã Gujjar, novamente um duplo discurso que reafirma a

\footnotetext{
${ }^{6} \mathrm{Na}$ verdade 0 motivo da acusação pouca importância tem. Em diversos momentos os Mastoi alteram a acusação. De tal forma que, nas palavras de Mai "a verdade está perdida na poeira dos relatos desse ou daquele, conforme pertença a esse ou àquele clã" (p. 23).
} 
superioridade de uma casta em função de outra. Apesar do que foi feito a Shakkur, ainda era necessário que os Gujjar pedissem perdão e para isso uma mulher da família foi escolhida. Aqui é a segunda maneira pela qual os Mastoi afirmaram sue poder.

A escolha de Mukhtar Mai para pedir perdão em nome da família era justificada, segundo a própria camponesa, pelo fato de que ela já havia sido casada e que embora não tivesse marido era respeitada em sua aldeia por ensinar o Corão. No entanto o pedido foi negado e Mai foi condenada, perante a jirga - o conselho de sua aldeia - ao estupro coletivo.

Eu, Mukbtar Bibi, filha primogênita do meu pai, Ghulam Farid, perdi a consciência de mim mesma, mas jamais esquecerei o rosto daqueles animais. Para eles, uma mulher não passa de um objeto de posse, honra e vingança. Casam-se com ela ou a violam de acordo com sua percepção de orgulho tribal. Sabem que uma mulher assim humilhada tem como único recurso o suicídio. Nem precisam de armas. 0 estupro a mata. 0 estupro é a arma derradeira. Serve para humilhar definitivamente o outro clã (p. 19).

Mukhtar Mai, após o estupro, foi levada para a sua casa sendo novamente acompanhada por seu tio e pai. Rapidamente a notícia se espalha pela aldeia e ora encontrando solidariedade ora sendo culpada do que the acontecera ela fica entre o desejo de se render ao suicídio ou de tentar lutar por alguma forma de vingança. Por fim, a despeito do que seria considerado a alternativa mais tradicional afinal, o suicídio "é o que as mulheres fazem no meu caso" (p. 25) - ela escolhe buscar por justiça.

\section{RESIGNAÇÃO, VIOLÊNCIA E RUPTURA}

Após o estupro, Mukhtar Mai ficou trancada em seu quarto. 0 horror que sofreu é tão grande que não consegue chorar, e por isso fica exilada no silêncio. Novamente condenada ao silêncio, sem nenhuma lágrima, são as mulheres de sua família que choram por ela. Após alguns dias toma sua decisão.

Imploro a minha mãe que me ajude a morrer. Que ela vá buscar ácido e que minha vida enfim termine, já que aos olhos dos outros eu estou morta. Minha mãe cai em soluços e me impede; não sai mais do meu lado dia e noite. Eu não consigo mais conciliar o sono e ela não me deixa morrer (p. 26). 
Mukhtar reconhece no estupro a morte que aqui assume um caráter social, ela já está morta aos olhos dos outros, dos que lhe são iguais e a partir dos quais percebe a si mesma. Além disso, sente-se culpada pelo que lhe aconteceu e 0 suicídio é a forma encontrada para fugir da vergonha e culpa. SUWICK (2002) ao entrevistar mulheres brasileiras vítimas de violência sexual aponta que o sentimento de culpa é, de fato, comum nesses casos. É um sentimento que ultrapassa culturas e fronteiras e se instala no corpo violado.

A figura da mãe e o apoio recebido são fundamentais para que Mai não se renda ao suicídio, como o fazem tantas outras mulheres que se encontram na mesma situação. De alguma forma é esse apoio recebido de sua família que a impulsiona e ela decide lutar. Além disso, Mukhtar se agarra à fé, às palavras escritas no Corão que recita de maneira incansável. Mais tarde, analisando sua trajetória ela própria reconhecerá que o estupro, o ato de subjugar o corpo feminino não é ensinado no Corão.

A partir daquele momento, nada mais seria habitual. Eu mesma já estava diferente. Não sabia como haveria de lutar e obter justiça como forma de vingança, mas o novo caminho estava na minha cabeça como o unico possível. Dele dependiam minha bonra e a de minha familia. Ainda que eu tivesse que morrer, não morreria bumilhada (p. 35).

Os conceitos de honra e família se confundem e permitem que essa paquistanesa resista. Ao ser convocada pela polícia local ela decide denunciar 0 que lhe ocorrera, apesar da tentativa dos policiais em convencê-la do contrário. A denúncia, no entanto, não deve ser compreendida como um simples relato. $\mathrm{Na}$ verdade nenhuma denúncia de violência deve ser encarada assim.

Contrapor-se ao silêncio pode ser o primeiro passo para o entendimento crítico da violência sexual, tanto por parte de suas vítimas como pela sociedade. Assim, ouvir os relatos de mulheres que sofreram violência é apreender os significados sentidos por elas atribuídos às experiências que viveram (ZUWICK, 2002, p. 36).

Mukhtar reconhece a importância de falar, de não ter a voz silenciada. "Falar da sua dor, de um segredo que consideramos vergonboso, liberta o espirito e o corpo. Eu não sabia" (p.82). Novamente é Zuwick (2002) quem demonstra que o silêncio não apenas contribui para a permanente submissão feminina como ainda garante a impunidade. Na verdade, foi a partir da denúncia e da cobertura que o caso recebeu de jornalistas que Mai obteve atenção 
internacional. Organizações que lutam em prol dos direitos humanos passam a apoiá-la e assim, a justiça de seu país é pressionada a tomar alguma medida .

Logo o caso Mukhtar Mai vai passando por diversas instanciais e modelos de julgamento. Não nos prenderemos ao acompanhamento de tal processo, o que nos parece fundamental é o processo pelo qual Mukhtar rompe com um padrão de subordinação e chega, inclusive a discutir com o primeiro-ministro quando em determinado momento do julgamento seus agressores - que haviam sido presos - são libertados.

Quem diria que eu seria capaz de falar desse jeito ao primeiro-ministro do governo do meu pais? Eu, Mukbtaran Bibi, de Weerwala, camponesa dócil e calada, transformada em Mai, a grande irmã respeitada, como mudei! Aqui estou sentada nessa belíssima poltrona diante do ministro, em atitude respeitosa, mas obstinada - e só o Exército seria capaz de me tirar dali sem a certeza de que esses bárbaros foram postos de novo na prisão, e da bora exata em que isso foi feito (p. 135).

Se compararmos a fala acima com a descrição da calada camponesa é provável que nos surpreendamos com a transformação pela qual ela passou. Ela mesma reconhece essa mudança. No entanto, a biografia de Mukhtar é generosa ao nos apresentar a trajetória de outra paquistanesa que também apresenta um processo de ruptura em relação ao sistema cultural ao qual se encontra subordinada. Trata-se de Naseem, filha de um dos policiais que faziam a escolta de Mukhtar.

A trajetória de Naseem nos oferece outros elementos para pensarmos a questão da submissão e da resistência. Tendo cursado faculdade de direito e feito mestrado em jornalismo, Naseem apresenta um nível educacional consideravelmente alto. Mukhtar descreve Naseem como uma mulher "viva, ativa, sem medo das palauras nem das pessoas, com idéias claras e facilidade para falar" (p.79) e por isso mesmo tão diferente da calada e simples camponesa que usava a impressão digital para "assinar" os relatórios prestados na delegacia.

\footnotetext{
${ }^{7}$ Muito embora tenha ocorrido a pressão de grupos que lutam pelos direitos humanos e direitos das mulheres no Paquistão assim que o caso tornou-se público é necessário reconhecer as dificuldades para esses grupos atuarem. Por um lado "os instrumentos internacionais de direitos das mulheres impõem obrigações e procedimentos mais brandos do que outras convenções internacionais; as instituições responsáveis pela aplicação e fiscalização desses instrumentos dispõem de poucos recursos e o seu campo de ação freqüentemente é circunscrito, fazendo com que o não-cumprimento das disposições por parte dos Estados seja bastante tolerado (AZAMBUJA e NOGUEIRA, 2008, p. 106). Por outro lado, há ainda o debate em torno da defesa ou não diversidade cultural (ESPINOLA, 2000). 
Podemos perceber a distância que se coloca entre Mukhtar e Naseem, ainda que ambas sejam mulheres submetidas às mesmas normas e tradições. 0 que as torna mais próximas talvez seja justamente a violência a qual estão sujeitas, é o que nos diz Naseem: "Qualquer que seja a sua posição social, seja analfabeta ou instruida, rica ou pobre, uma mulher vítima de violência é também vítima de intimidação" (p. 115). No entanto, ainda assim é possível considerar que devido à especificidade de sua trajetória Naseem teve acesso a certo tipo de conhecimento que a fez deixar de ver como naturais alguns costumes que legitimam a submissão da mulher. Adquiriu uma percepção que rompe, em larga escala - ainda que não completamente -, com algumas das normas e tradições de onde vive e que a faz pensar em uma igualdade entre homens e mulheres. Assim, para Naseem:

Os homens e as mulheres são iguais. Temos os mesmos direitos. Tenho consciência de que o islã conferiu uma superioridade aos bomens, mas eles se aproveitam disso para nos dominar totalmente. Você tem que obedecer ao pai ao irmão, ao tio, ao marido e, por fim, a todos os bomens da aldeia, a provincia e do país inteiro! (p. 81).

De fato, é apenas a partir do momento que o indivíduo toma consciência de que as leis sociais não são de fato naturais que a violência simbólica presente nas relações torna-se evidente. Dito como outras palavras, somente a partir do momento em que aquilo que é tido como natural e que impõe papéis, representações e determina as maneiras pelas quais os indivíduos devem agir e pensar é desconstruído que o individuo adquire uma consciência crítica. De fato, Naseem rompeu com algumas normas e regras impostas às mulheres de seu país, mas ainda assim é preciso reconhecer que ela se encontra submissa às mesmas tradições contra as quais luta. Essa visão nos é dada por Mai:

Apesar de instruida, Naseem também tem que respeitar a tradição, e bá muito tempo já foi escolbido um marido para ela. Mas ele não corresponde ao seu ideal. Por isso, sem querer demonstrar falta de respeito pelos pais, ela tenta escapar dessa união. Sem confrontos nem discussões. Ela tem 27 anos, está estudando e, como ele não se manifesta, ela espera... que ele acabe desistindo, que se canse ou que conbeça outra pessoa. De qualquer maneira, ela diz que resistirá por tanto tempo quanto for preciso (p. 91).

Segundo Gisburg (1987, p. 27) "assim como a língua, a cultura oferece ao indivíduo um horizonte de possibilidades latentes - uma jaula flexível e invisível 
dentro do qual se exercita a liberdade condicionada de cada um". Vemos na fala expressa acima, um exemplo do que Ginzburg se referia ao pensar em uma liberdade condicionada. Naseem está sujeita a mesma tradição que Mai, ainda assim, experimentou uma diferente forma de socialibilidade que, embora a tenha permitido adquirir uma visão mais crítica a respeito da situação das mulheres de seu país não muda o fato de que as invisíveis jaulas da cultura continuam lá, talvez um pouco mais flexíveis, mas ainda assim fortes o bastante para que ela mantenha a palavra dada por seus pais ao acertarem o casamento.

É fundamental compreendermos a importância que Naseem representou na biografia da camponesa. Mukhtar Mai encontrou alguém que lhe era muito próximo, mulher tal qual ela, sujeita as mesmas tradições e normas, mas ainda assim, uma mulher tão diferente que em determinado momento nos faz pensar que é um Outro - no sentido utilizado por Todorov (1991) - muito distante.

Nessa mesma perspectiva devemos pensar a história de Mai para as demais mulheres de seu país. Diversas organizações internacionais já lutavam pelos direitos das mulheres paquistanesas, no entanto, era preciso que essas mulheres pudessem vislumbrar um ícone que lhes fosse próximo. Não um símbolo de uma liberdade estrangeira, mas algo que fizessem parte daquele mesmo mundo.

Contra a minha vontade eu me tornei um simbolo para todas aquelas que são submetidas à violência dos patriarcas e dos chefes de tribos, e se esse simbolo atravessou as fronteiras, certamente servirá aos interesses do meu país. Está aí a verdadeira honra de minha pátria, permitir que uma mulher, analfabeta ou não, lute em voz alta contra a injustiça sofrida (p. 141).

Assim, é exatamente o papel que Mukhtar passa a representar nesse país que pode apresentar um caráter realmente revolucionário. Mas além da fala, é importante apontar outro importante passo na luta pela conquista de direitos das mulheres desse país. Trata-se de uma escola que Mukhtar conseguiu abrir em sua aldeia e onde passou a ensinar a meninos e meninas. Em diversos momentos de seu relato Mukhtar Mai demonstra sua dor por não saber ler. Ela sabe, por sua própria experiência, que o que é ensinado a uma menina é muito pouco, nada é dito abertamente e o aprendizado vem através do Corão ou daquilo que as crianças conseguem ouvir das conversas dos adultos.

E o que a gente aprende com a mãe na minha província tão distante? A fazer o chapatis, cozinhar o arroz e o dal, lavar a roupa de cama, pendurá-la no tronco das palmeiras para secar, cortar a grama, o trigo, 
a cana-de-açúcar, preparar o chá, pôr os menores para dormir e buscar água na bomba. Uma mãe fez tudo isso antes de nós, e, antes dela, sua mãe também. Até que chega a hora de casar. Fazer filhos, e tudo vai continuando assim, de mulher em mulher (p. 73).

Mais tarde as mães fazem comentários em voz alta, para que as filhas ouçam. Muitas vezes são críticas (...) Fora a oração e a recitação do Corão, é a única educação que recebemos. E ela nos ensina a desconfiança, a obediência, a submissão, o temor, o respeito total ao homem (p. 86).

Assim, para Mai a escola representa uma possibilidade de transformação. "Daqui a alguns anos, essas menininhas já terão suficientes conhecimentos para enfrentar a vida de uma outra maneira, espero" (p. 108) Nesse sentido, nos colocamos na mesma perspectiva de Soihet (1997, p. 14) para quem "a educação é elemento fundamental na tomada de consciência das mulheres de sua condição subalterna, ao mesmo tempo em que lhes proporciona o instrumental para ultrapassar essa condição". Podemos acreditar que a escola pode configurar um palco privilegiado no campo das sociabilidades.

\section{CONSIDERAÇÕES FINAIS}

Conforme tivemos a oportunidade de perceber ao logo do presente trabalho Mukhtar Mai em diversos momentos demonstra ter incorporado os elementos de sua tradição. A obediência, a resignação, o reconhecimento do poder exercido não apenas pelos homens como também pelos Mastoi. Na verdade, nada disso poderia ser diferente. Mukhtar ao logo de sua vida se confrontou com uma estrutura onde seu papel estava desde muito cedo definido. Os bens simbólicos que os Mastoi possuem tornam claros que eles de fato detêm um poder que os inscreve em uma lógica de distinção. Na verdade, é preciso reconhecer que aqui não se trata apenas da representação de uma casta, mas sim do papel assumido por homens guerreiros e que, por isso mesmo, precisam a todo custo reforçar seu poder - que não raramente está relacionado à virilidade masculina.

No entanto, embora tenha interiorizado essa estrutura é importante destacar que Mukhtar Mai foi capaz de transgredir as leis que - embora não tenham sido escritas, são reconhecidas por todos, homens ou mulheres de quaisquer castas - condenam as mulheres ao silêncio e a culpa por terem sido violadas. É esse movimento de ruptura que merece ser destacado. Logicamente diversos fatores influíram nessa mudança. Primeiramente o apoio da família. 
Segundo o relato Mukhtar em nenhum momento foi condenada ou mesmo abandonada por seus pais. E mesmo após o estupro, sua mãe passou a vigiá-la com medo de que cometesse o suicídio, ainda que isso, possivelmente, limpasse a honra da família. Assim, é preciso reconhecer que a história de Mukhtar Mai não pode ser considerada representativa da sociedade de onde emerge. A própria Mai reconhece a excepcionalidade do seu caso:

Quantas poderão contar, como eu, com o apoio da familia? Quantas terão a sorte de que um jornalista relate os fatos, de que as associações de direitos humanos se mobilizem, a ponto de obrigar o governo a intervir? Existem tantas mulheres analfabetas no vale do Indus! Tantas mulheres que serão rejeitadas e deixadas indefesas pelos maridos e pelas familias, privadas de honra e rendimentos. Simples assim (p. 72).

Se pensarmos a cultura como um processo calcado única e exclusivamente na continuidade histórica, então a atitude de Mukhtar seria algo simplesmente impossivel de ser compreendido. Assim é preciso reconhecer que a tradição comporta também espaços de mudanças, ou, nas palavras de Sahlins (2003, p. 76) que "a continuidade dos costumes é sempre vulnerável à ruptura". Nesse sentido é possível pensar que esse movimento de resistência, cuja figura de Mukhtar Mai talvez seja emblemática, possa representar o começo de uma transformação que nasce dentro da própria cultura de onde emerge.

É o próprio Sahlins (2003) que, ao se debruçar sobre os paradigmas da teoria antropológica em torno do conceito de cultura, lança a seguinte questão: a cultura nasce das ações ou as ações são balizadas por elementos culturais? A leitura da biografia de Mai nos permitiu perceber o peso que a cultura exerce nas práticas e representações de um povo, mas nos permitiu também constatar que, essa mesma cultura não age como um código imutável apreendido e reproduzido de maneira autônoma e inflexível. É preciso reconhecer que cultura e subjetividade se atravessam e se modificam. Não devemos pensar no indivíduo sem os imperativos que a sociedade impõe, mas qualquer análise que não perceba a importância e o poder de cada indivíduo na permanência e/ou transformação desses imperativos desconsidera aquilo que é fundamental na humanidade: a possibilidade de ruptura.

"Com a minha coragem, dizem, eu expus a condição de vida das mulheres do meu país, e outras seguirão o meu caminho." 


\section{REFERÊNCIAS}

AZAMBUJA, Mariana Porto Ruwer de; NOGUEIRA, Conceição. Introdução à violência contra as mulheres como um problema de Direitos Humanos e de Saúde Pública. Saúde e Sociedade. São Paulo, v.17, n.3, 2008.

BOURDIEU, Pierre. Razões práticas: sobre a teoria da ação. São Paulo: Papirus, 1996.

. A miséria do mundo. Petrópolis: Vozes, 1998.

. A dominação masculina. Rio de Janeiro: Bertrand Brasil, 1999.

. Novas considerações sobre a dominação masculina. In: Lopes, Marta et alli. Gênero e Saúde. Porto Alegre: Artes Médicas, 1999.

BR00KS, Geraldine. Nove partes do desejo: o mundo secreto das mulheres islâmicas. Rio de Janeiro: Gryphus, 1996.

CHALHOUB, Sidney. Trabalho, lar e botequim: o cotidiano dos trabalhadores no Rio de Janeiro da Belle Époque. São Paulo: Brasiliense, 1986.

CHARTIER, Roger. A bistória cultural: sobre práticas e representações. Rio de Janeiro: Ed. Bertrand Brasil, 1990.

ESPINOLA, Claudia Voigt. A mulher no Islã: gênero, violência e Direitos Humanos. In: X Jornadas sobre Alternativas religiosas - sociedad y religion en el Tercer Milenio. Buenos Aires, 2000 [CD-room].

GINZBURG, Carlo. O queijo e os vermes: o cotidiano e as idéias de um moleiro perseguido pela inquisição. São Paulo: Cia das Letras, 1987.

LARAIA, Roque de Barros. Cultura: um conceito antropológico. Rio de Janeiro: Jorge Zahar, 2006

MAI, Mukhtar \& CUNY, Marie-Therese. Desonrada. Rio de Janeiro: BestSeller, 2007.

SAHLINS, Marshall. Cultura e razão prática - dois paradigmas da teoria antropológica. Rio de Janeiro: Zahar, 2003.

SOIHET, Rachel. Violência simbólica: saberes masculinos e representações femininas. Estudos Feministas. Florianópolis/Rio de Janeiro: IFCS/UFRJ, 1997

THOMPSON, Edward Palmer. Costumes em comum. São Paulo: Cia das Letras, 1998. 
TODOROV, Tzevtan. A conquista da América: a questão do outro. São Paulo: Martins Fontes, 1991.

ZUWICK, Ana Maria. A violência sexual e suas repercussões na subjetividade feminina. Gênero: Revista Transdisciplinar de Estudos de Gênero. NUTEG v.2, n.2. Niterói: EdUFF, 2000. 